\title{
Isocyanate hazard from wire insulation: an old hazard in a new guise
}

\author{
DERMOD P. G. PAISLEY \\ Ministry of Health and Social Services, Belfast, Northern Ireland
}

\section{Polyurethanes and the diisocyanates}

The isocyanate group is chemically highly reactive, and diisocyanates will combine with many organic compounds. The industrially useful reactions involve the combination of a disocyanate with a resin, usually an organic polyhydric alcohol, to form a high-molecular-weight polymer of the polyurethane type.

Polyurethanes are used as paints and varnishes, surface coatings, flexible and rigid foams in upholstery and soft toys, in thermal insulation in the lower temperature ranges, and in sound insulation. Polyurethane foams are offered for thermal insulation in buildings (e.g., foamed into cavity walls) for warm and cold houses and for refrigerated rooms, including refrigerated compartments in ships. Additional uses include combating oil contamination in water and acoustic cladding to reduce to tolerable levels the noise produced by high performance engines.

\section{Respiratory outbreak}

In March, 1967 there occurred an outbreak of respiratory disease among persons working in a factory manufacturing electrical goods. The complaints were of breathlessness and cough, with breathlessness, occurring in spasms, as the prominent feature. The attacks occurred at work, and at night in bed, when they were associated with fever and sweating. The persons affected were employed winding coils and dipping terminals.

Cases arose sporadically over a period of months. In the intervening periods no trouble was experienced. By August, 40 workers ( 39 women and 1 man) had been affected. Most of them had been doing the jobs for many years without complaint. They alleged that they were being affected by fumes from the solder pots. Seven hundred workers are employed in this factory -600 women and 100 men.
The Works Medical Officer informed me that in those cases presented to him (he acts in a part-time capacity and visits the factory twice weekly) he found no physical signs in the lungs except in three persons known to suffer from chronic bronchitis. Two of the others, who were brought to him with obvious dyspnoea, had marked nasal congestion.

The coil winding and terminal dipping sections are situated adjacent to one another in the factory.

There were puzzling features in this problem. First, the cases arose in a random manner. Conditions in the factory, which are excellent, appeared to be constant, yet from time to time some persons were affected in the manner described, and in the intervening periods no trouble was experienced. Secondly, not all the cases occurred at the benches where the solder pots stand. The solder in these pots is maintained constantly in a molten state at $360^{\circ} \mathrm{C}$. Moreover, of the 32 solder pots, exhaust ventilation had been applied to 28 , the remaining 4 having no exhaust ventilation. This operation has been conducted for many years in this and numerous other factories without any exhaust ventilation and without, apparently, giving rise to any trouble. The application of exhaust ventilation to the 28 pots had been done on general principles and because the hoods defined the area of work and tidied up the operation. All the cases which arose among those employed at terminal dipping occurred at the ventilated benches. None occurred at the bench with the four unventilated solder pots.

Observation of the work in progress and examination of all the substances handled was carried out in detail. The exhaust ventilation at the ventilated benches was carefully examined. Nothing useful emerged from these investigations.

During discussion, it was suggested that the trouble might have been of the nature of farmer's lung, caused by fungal spores liberated from the wet clay of adjacent excavations carried out to correct 
defects in the floor at one end of the factory, but this area had been walled off from the main factory.

The evidence appeared to me to indicate a respiratory irritant and bronchial sensitizer such as a diisocyanate. I enquired if any wall or floor treatments with polyurethanes had been carried out and if any new methods or materials had been used. I was informed that a new wire, believed to be polyurethane-covered, had recently been introduced. I asked to see the wire actually in use and observed what was, to me, the surprising manoeuvre of applying the hot soldering iron directly to the insulating coating on the wire. I wondered if, when polyurethane was heated to destruction in this manner, diisocyanate vapour was released to atmosphere. It was decided to make two special investigations.

\section{Special investigations}

The following were undertaken:

1 A microbiological and immunological investigation to test the farmer's lung theory

2 A chemical investigation to determine (a) whether or not the covering on the wire was a polyurethane, and $(b)$ if it was, whether, when this polyurethane was heated to destruction, diisocyanate vapour was released to atmosphere.

1 The microbiological investigation, which included testing of the serum of affected workers

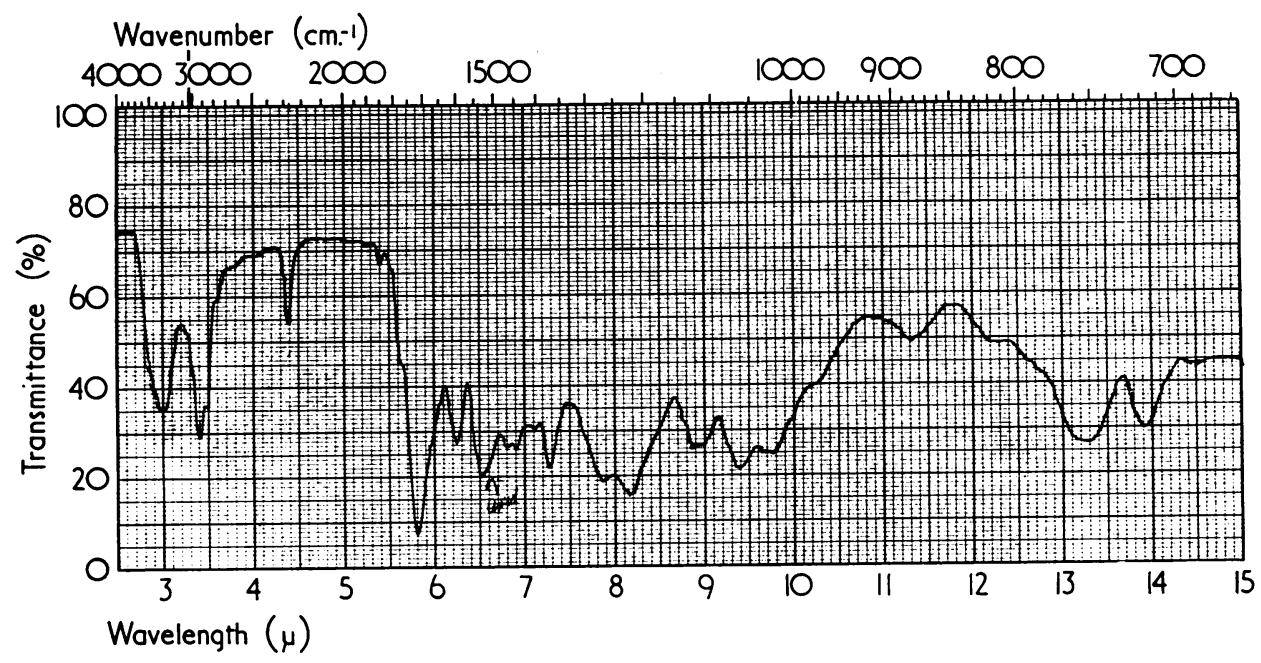

FIG. 1. Infra-red spectrum of pyrolytic products of wire covering showing absorption band at $4.4 \mu$.

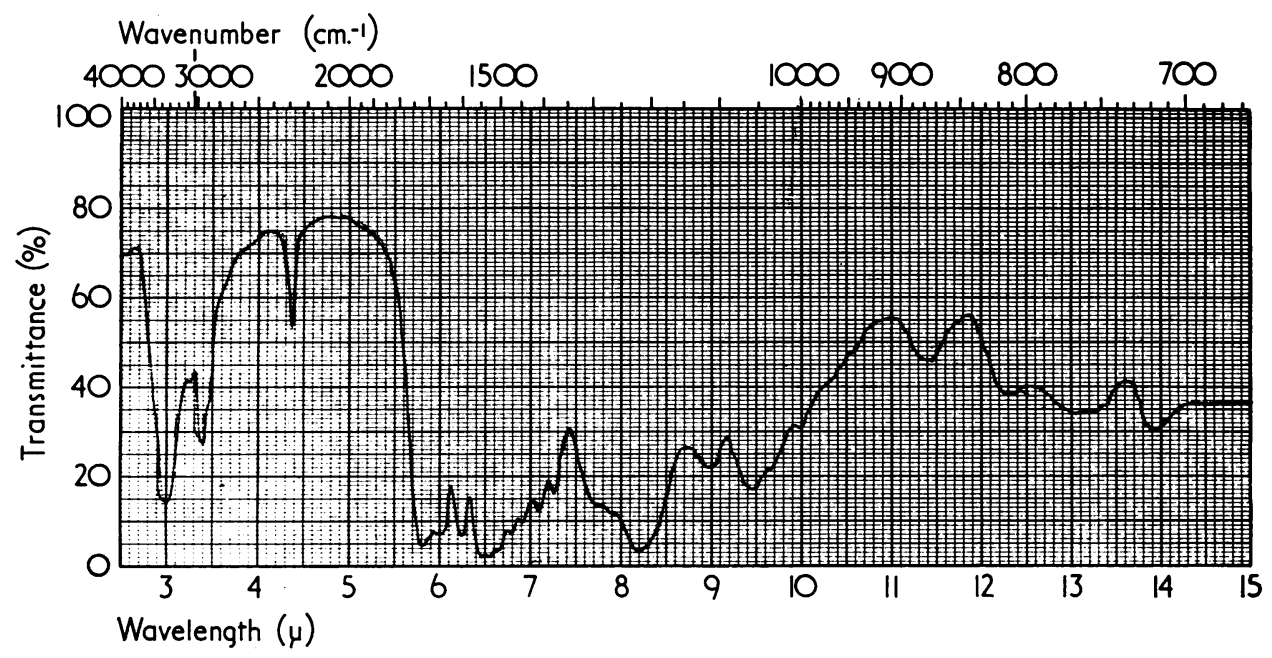

FIG. 2. Infra-red spectrum of vapours evolved during soldering showing absorption band at $4.4 \mu$. 
and air sampling and dust sampling at the factory followed by culturing, was negative in all respects.

2 The investigation of the wire covering revealed that this material was a polyurethane and that when it is heated to destruction, isocyanate vapours are released to atmosphere. Subsequently, enquiries of the manufacturer of the wire disclosed that the covering was polyurethane based on toluene diisocyanate.

Nitriles and isocyanates produce absorption bands at $4.4 \mu$ when scanned on an infra-red spectrophotometer. This position is relatively free from other well-defined absorption bands. Absorption bands at $4.4 \mu$ were found when the vapours evolved during soldering were absorbed in wash bottles of petroleum ether and the resulting solutions scanned. Decomposition of polyurethanes occurs at $220^{\circ} \mathrm{C}$. $-275^{\circ} \mathrm{C}$., producing isocyanates and $\mathrm{N}$-oxides (Figs 1 and 2). The temperature of a soldering iron in normal soldering operations is $300^{\circ} \mathrm{C}$.

The picture then appeared to be complete, and some of the more puzzling aspects were explained. The onset of symptoms coincided with the introduction of the polyurethane-covered wire. The wire was not in constant use but was used intermittently for winding a particular type of coil. The fact that all the cases which occurred in the terminal dipping section were among those working at the ventilated benches appeared also to be explained because these benches were adjacent to the coil winders who, by applying hot soldering irons to polyurethane, were releasing small quantities of isocyanate vapour to atmosphere at frequent intervals.

\section{Conclusions}

This finding appears to be important in a number of respects. There is the immediate hazard in relation to the work of coil winding using polyurethanecovered wire. There are also remote hazards, indicated by this finding, related to the ever widening use of these polyurethane materials. When buildings in which are incorporated large quantities of polyurethane foams, surface applications, etc. are set alight, there might be a serious hazard to firemen and others engaged in combating the fire. The position appears to be even more serious in the case of fire at sea when refrigerated compartments in ships become involved or in engine rooms where polyurethane cladding of engines has been used for noise suppression, because in these circumstances those engaged in putting out the fires would probably be working in confined spaces and might be exposed to high concentrations of isocyanate vapours.

My thanks are due to Professor K. B. Fraser, Professor of Microbiology, Queen's University, Belfast for the 'farmer's lung' investigation, to Dr. A. J. Howard, M.A., Ph.D., F.R.I.C., Director, Department of Industrial and Forensic Science, Ministry of Commerce, Northern Ireland, to Mr. T. J. McCullins, M.Sc., A.R.I.C., C.Eng., Principal Scientific Officer, Department of Industrial and Forensic Science who carried out the chemical investigation, to Dr. J. E. Sutcliffe, Works M.O., to Dr. F. F. Main, Chief Medical Officer, Ministry of Health and Social Services Northern Ireland for permission to publish this report, and to Dr. T. A. Lloyd Davies for valuable advice.

Received for publication April 19, 1968.

\title{
Munchausen's syndrome simulating caisson disease
}

\author{
J. H. KEMP AND J. G. MUNRO \\ H.M. Dockyard, Chatham, Kent
}

We report a patient who was transferred from a London hospital with apparent caisson asphyxia and was treated in the compression chamber of H.M. Dockyard, Chatham which, in addition to its naval uses, treats civilian cases from south-east
England. He was found to have Munchausen's syndrome which has not been reported with this presentation before.

At 7.0 p.m. on January 8, 1968 a small, one-eyed, elderly man smelling of alcohol arrived from hospital 